\title{
Efficacy of weed control methods in spring wheat
}

\section{Skuteczność metod regulacji zachwaszczenia w pszenicy jarej}

\author{
Jan Buczek, Wacław Jarecki, Dorota Bobrecka-Jamro
}

\section{Summary}

The study was conducted between the years 2008 and 2010 at the Experimental Station near Rzeszow Krasne. The experiment was carried out on brown soil developed from loess, classified as IIla bonitation class, of good wheat complex, containing $\mathrm{P}_{2} \mathrm{O}_{5}-210 \mathrm{mg} / \mathrm{kg}$ of the soil, $\mathrm{K}_{2} \mathrm{O}-140 \mathrm{mg} / \mathrm{kg}$ of the soil and $\mathrm{pH}$ in $\mathrm{KCl}-6.5$. The aim of the study was to determine the yield and weed infestation of Monsoon and Parabola varieties of the wheat spring crop in regards to different weed control methods, i.e.: mechanical, mechanical-chemical and chemical, using full and reduced doses of Mocarz 75 WG herbicide (tritosulfuron + dicamba). Similar efficacies of weed control in wheat spring varieties were found in the treatments with recommended herbicide dose and double crop harrowing supplemented with a half dose of herbicide. The effect of variety on the total degree of weed control and the reduction of the air-dry weight of weeds was not unequivocally determined.

A significantly higher grain yield of both wheat varieties was obtained from a full dose and a dose reduced by $50 \%$ applied after harrowing as compared to the treatments with a half dose of herbicide and mechanical control.

Key words: integrated method, weed control, spring wheat, yield

\section{Streszczenie}

Badania przeprowadzono w latach 2008-2010 w Stacji Doświadczalnej Krasne koło Rzeszowa. Doświadczenie zlokalizowane było na glebie brunatnej wytworzonej z lessu, zaliczanej do klasy bonitacyjnej Illa, kompleksu pszennego dobrego, o zawartości $\mathrm{P}_{2} \mathrm{O}_{5}-$ $210 \mathrm{mg} / \mathrm{kg} \mathrm{i} \mathrm{K}_{2} \mathrm{O}-140 \mathrm{mg} / \mathrm{kg}$ gleby oraz $\mathrm{pH} \mathrm{w} \mathrm{KCl}-6,5$. Celem badań było określenie plonowania oraz zachwaszczenia łanu pszenicy jarej odmian Parabola i Monsun pod wpływem kilku sposobów regulacji zachwaszczenia: mechaniczny, mechaniczno-chemiczny oraz chemiczny z zastosowaniem pełnej $\mathrm{i}$ obniżonej dawki herbicydu Mocarz 75 WG (tritosulfuron + dikamba). Zbliżone efekty chwastobójcze w odmianach pszenicy jarej stwierdzono na obiektach, gdzie stosowano zalecaną dawkę herbicydu i dwukrotne bronowanie zasiewów uzupełnione połową dawki herbicydu. Nie stwierdzono jednoznacznego wpływu odmiany na stopień zniszczenia chwastów ogółem, a także na redukcję powietrznie suchej masy chwastów. Uzyskano istotnie wyższy plon ziarna obu odmian pszenicy z obiektów z pełną oraz zredukowaną o 50\% dawką po wcześniejszym bronowaniu w porównaniu z obiektami z połową dawki herbicydu i regulacją mechaniczną.

Słowa kluczowe: metody integrowane, regulacja zachwaszczenia, pszenica jara, plon

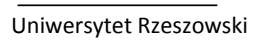

Katedra Produkcji Roślinnej

Zelwerowicza 4, 35-601 Rzeszów

janbuczek7@gmail.com 


\section{Wstęp / Introduction}

Zdolności konkurencyjne zbóż jarych w stosunku do flory segetalnej są zróżnicowane, co powoduje, że występujące chwasty $\mathrm{w}$ ilościach powyżej progów szkodliwości przyczyniają się nie tylko bezpośrednio do obniżenia plonu lecz również do pogarszania jego jakości wskutek porastania i porażenia chorobami ziarna. Stosowanie w zbożach jarych herbicydów i ich oddziaływanie na ograniczenie zachwaszczenia, a także na plon oraz jakość, determinowane jest nie tylko warunkami siedliskowymi, przebiegiem pogody w sezonie wegetacyjnym oraz agrotechniką, ale zależy także od składu chemicznego preparatów oraz ich dawek (Domaradzki i wsp. 2003; Krawczyk i Kaczmarek 2008).

Ograniczenie ilości środków ochrony roślin w tym herbicydów aplikowanych w zbożach, w obniżonych dawkach ma uzasadnienie zarówno ekonomiczne, agrotechniczne, jak i ekologiczne, co potwierdzono w niektórych badaniach zarówno w stosunku do gatunków zbóż (Salonen 1992; Knezevic i wsp. 2003; Brzozowska i Brzozowski 2008; Wesołowski i Boniek 2009), jak i ich odmian (Urban i wsp. 2011; Haliniarz i Kapeluszny 2012).

Jednym $\mathrm{z}$ elementów integrowanych metod regulacji zachwaszczenia przeciwdziałających zmniejszeniu skuteczności zredukowanych dawek herbicydów w zbożach, ale także $\mathrm{w}$ innych gatunkach roślin są metody łączone, mechaniczno-chemiczne $\mathrm{z}$ użyciem znacznie obniżonych dawek herbicydów. Zaletą tych metod jest ograniczenie zanieczyszczenia środowiska i produktów roślinnych pozostałościami substancji czynnych, a także dość duża skuteczność chwastobójcza, przy mniejszych kosztach chemicznego odchwaszczania (Kierzek i Wachowiak 2004; Swanton i wsp. 2008).

Celem badań było określenie poziomu plonowania oraz stanu i stopnia zachwaszczenia łanu pszenicy jarej pod wpływem bronowania oraz stosowania zalecanej i obniżonej dawki herbicydu Mocarz 75 WG (tritosulfuron + dikamba). Dokonano także oceny przydatności metody mechaniczno-chemicznej, w której aplikację połowy dawki herbicydu poprzedzono bronowaniem zasiewów pszenicy.

\section{Materiały i metody / Materials and methods}

Prezentowane wyniki pochodzą ze ścisłego doświadczenia polowego przeprowadzonego w latach 2008-2010 w Stacji Doświadczalnej Wydziału Biologiczno-Rolniczego Uniwersytetu Rzeszowskiego w Krasnem (5003' N, $\left.22^{\circ} 06^{\prime} \mathrm{E}\right)$.

Doświadczenie zlokalizowane było na glebie brunatnej wytworzonej z lessu, zaliczanej do klasy bonitacyjnej IIIa, kompleksu pszennego dobrego, o zawartości $\mathrm{P}_{2} \mathrm{O}_{5}-$ $210 \mathrm{mg} / \mathrm{kg}$ i $\mathrm{K}_{2} \mathrm{O}-140 \mathrm{mg} / \mathrm{kg}$ gleby oraz $\mathrm{pH} \mathrm{w} \mathrm{KCl}-6,5$. Eksperyment założony był jako 2-czynnikowy według schematu losowanych podbloków i prowadzony w 4 powtórzeniach.

Czynnikami doświadczenia były:

I. Odmiany pszenicy jarej (Parabola, Monsun),

II. Sposoby odchwaszczania pszenicy jarej (A. Obiekt kontrolny - bez odchwaszczania; B. Bronowanie 2-krotne; C. Mocarz 75 WG (tritosulfuron + dikamba) - 200,0 g/ha: D. Bronowanie 2-krotne + Mocarz 75 WG (tritosulfuron + dikamba) - 100,0 g/ha; E. Mocarz $75 \mathrm{WG}-100,0 \mathrm{~g} / \mathrm{ha})$.

Herbicyd stosowano w fazie krzewienia zboża $(\mathrm{BBCH}$ 21-22). Dwukrotne bronowanie zasiewów pszenicy jarej wykonano $\mathrm{w}$ fazie szpilkowania $(\mathrm{BBCH} 10-11)$ oraz w fazie 3-4 liści (BBCH 13-14).

Efekt działania badanych sposobów regulacji zachwaszczenia oceniano wyrażając $\mathrm{w}$ procentach masę zniszczonych chwastów w stosunku do kontroli.

Siew obu odmian pszenicy jarej w latach badań przeprowadzono w pierwszej połowie kwietnia. Przedplonem pszenicy w latach badań był groch siewny. Nawożenie mineralne $\mathrm{w} \mathrm{kg}$, w przeliczeniu na 1 ha wynosiło: $\mathrm{N}-70$, $\mathrm{P}-26$ i K - 75. Azot stosowano w dwóch dawkach dzielonych: $40 \mathrm{~kg}$ przedsiewnie i $30 \mathrm{~kg} \mathrm{w}$ fazie strzelania w źdźbło (BBCH 34-35). Gęstość siewu uprawianych w doświadczeniu pszenic wynosiła 450 ziaren na $1 \mathrm{~m}^{2}$. Ziarno zaprawiono przed siewem zaprawą Baytan Universal 19,5 WS.

Tabela 1. Warunki meteorologiczne w okresie badań

Table 1. Meteorological conditions during the study

\begin{tabular}{|c|c|c|c|c|c|c|}
\hline \multirow{3}{*}{ Rok - Year } & \multicolumn{5}{|c|}{ Miesiąc-Month } & \multirow{2}{*}{$\begin{array}{c}\text { Średnia/Suma } \\
\text { Mean/Sum }\end{array}$} \\
\hline & IV & $\mathrm{V}$ & VI & VII & VIII & \\
\hline & \multicolumn{5}{|c|}{ temperatura - temperature $\left[{ }^{\circ} \mathrm{C}\right]$} & \\
\hline 2008 & 9,1 & 13,6 & 18,1 & 18,9 & 18,8 & 15,7 \\
\hline 2009 & 11,1 & 13,8 & 16,6 & 20,7 & 19,4 & 16,3 \\
\hline 2010 & 8,9 & 14,3 & 17,9 & 20,8 & 19,5 & 16,3 \\
\hline \multirow[t]{2}{*}{ Wielolecie - Long-term 1970-2005 } & 8,7 & 13,9 & 17,0 & 19,0 & 18,2 & 15,4 \\
\hline & \multicolumn{5}{|c|}{ opady - rainfall [mm] } & \\
\hline 2008 & 45,5 & 105,3 & 86,7 & 117,6 & 55,3 & 410,4 \\
\hline 2009 & 3,7 & 102,6 & 146,4 & 98,0 & 21,8 & 372,5 \\
\hline 2010 & 49,9 & 177,0 & 126,1 & 200,2 & 98,6 & 651,8 \\
\hline Wielolecie - Long-term 1970-2005 & 50,6 & 80,8 & 82,0 & 88,2 & 68,8 & 370,4 \\
\hline
\end{tabular}


Do ochrony chemicznej łanu pszenicy zastosowano dodatkowo: fungicyd Tilt Plus $400 \mathrm{EC}$ (propikonazol + fenpropidyna) w dawce 1,0 1/ha, insektycyd Fastac 100 EC (alfa-cypermetryna) $\mathrm{w}$ dawce $0,12 \mathrm{l} / \mathrm{ha}$ oraz regulator wzrostu Moddus 250 EC (trineksapak etylu) - 0,4 1/ha. Środki ochrony roślin aplikowano przy użyciu opryskiwacza plecakowego Aporo, o ciśnieniu 0,25 MPa i prędkości około $4 \mathrm{~km} / \mathrm{h}$, stosując ciecz opryskową w ilości 300 l/ha.

Zachwaszczenie łanu odmian pszenicy jarej oceniano metodą botaniczno-wagową. Ocenę zachwaszczenia prowadzono przed zbiorem pszenicy jarej na powierzchni $0,5 \times 0,5 \mathrm{~m}^{2}$, na dwóch wybranych losowo miejscach każdego poletka. Chwasty posegregowano na gatunki i policzono oraz oznaczono powietrznie suchą masę.

$\mathrm{Na}$ podstawie zbioru z poletka określono plon ziarna obu odmian pszenicy przy wilgotności 15\%.

Wyniki opracowano statystycznie za pomocą analizy wariancji. Istotność wpływu czynników doświadczenia na badane cechy określono testem Tukeya, obliczając najmniejszą istotną różnicę przy poziomie istotności 0,05 .

Okres badawczy charakteryzował się zmiennością pogody zwłaszcza w przypadku warunków opadowych (tab. 1). W roku 2009 wystapiła najmniejsza suma opadów, która była zbliżona do średniej sumy z wielolecia, przy nierównomiernym jednak rozkładzie opadów w okresie wegetacji pszenicy. Obfitującym w opady był rok 2010, w którym, w maju i lipcu spadło dwukrotnie więcej deszczu od średnich miesięcznych z wielolecia. Rok 2008 charakteryzował się wyższą sumą opadów w stosunku do wielolecia, przy czym średnie miesięczne nie odbiegały znacznie od wieloletnich. Temperatury powietrza w analizowanym okresie badań były mniej zróżnicowane zarówno w zakresie średnich rocznych i miesięcznych $\mathrm{w}$ porównaniu $\mathrm{z}$ wieloleciem.

\section{Wyniki i dyskusja / Results and discussion}

Poziom zachwaszczenia łanu pszenicy jarej determinowany był głównie stosowanym sposobem regulacji zachwaszczenia (tab. 2).

Niezależnie od odmiany liczba chwastów krótkotrwałych oraz ogółem była istotnie mniejsza na obiektach z zalecaną dawką herbicydu oraz bronowaniem uzupełnionym połową dawki w porównaniu $\mathrm{z}$ obiektami, na którym zastosowano tylko bronowanie odchwaszczające i 50\% dawki herbicydu.

Podobnie kształtowała się liczba chwastów wieloletnich, zależności tych jednak nie potwierdzono statystycznie. Porównując odmiany pszenicy, za bardziej konkurencyjną wobec chwastów można uznać odmianę Parabola, o czym świadczy mniejsza choć nieistotna liczba chwastów w porównaniu odmianą Monsun.

Flora gatunków chwastów w zasiewach obu uprawianych odmian pszenicy była podobna i cechowała się jednakową różnorodnością gatunkową (tab. 3). W prowadzonych przez trzy lata badaniach stwierdzono obecność 17 gatunków chwastów. Gatunki krótkotrwałe reprezentowane były przez: Chenopodium album, Stellaria media, Viola arvensis i Galium aparine. Na wszystkich obiektach doświadczenia dominującym gatunkiem była Ch. album, której udział w ogólnej liczbie chwastów wynosił od 22,2 do 35,2\%. Badania Krawczyka (2009) oraz Wesołowskiego i Bońka (2009) dowodzą, iż Ch. album, ale również $S$. media i $V$. arvensis są jednymi $\mathrm{z}$ najliczniej reprezentowanych gatunków chwastów segetalnych występujących w odmianach pszenicy jarej i ozimej. Wśród gatunków wieloletnich najczęściej występował: Cirisum arvense, Convolvulus arvensis oraz Elymus repens.

Tabela 2. Liczba chwastów w łanie pszenicy w zależności od sposobów regulacji zachwaszczenia i odmian (średnie z lat 2008-2010) Table 2. Number of weeds in the wheat canopy in dependence on weed control methods and cultivars (means for 2008-2010)

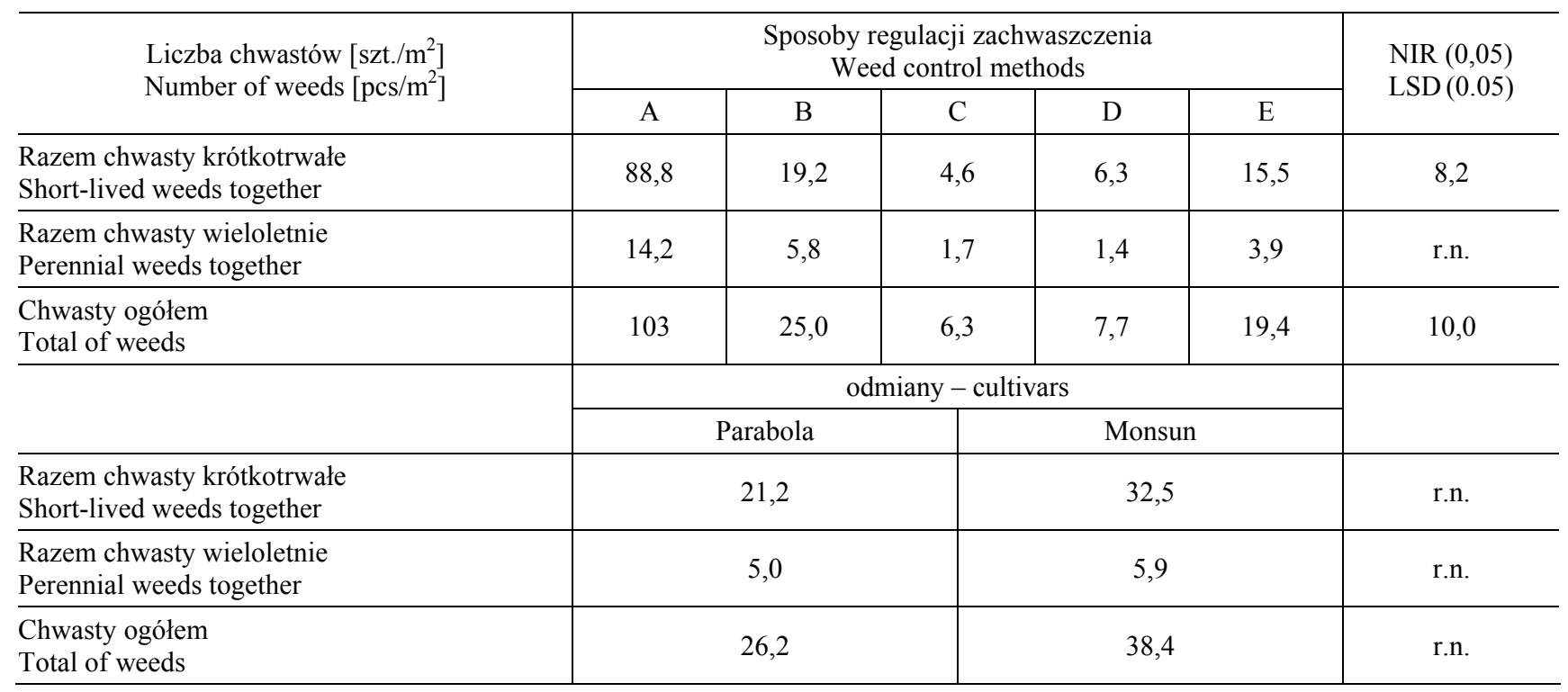

r.n. - różnice nieistotne - not significant differences

A - Kontrola - Control

B - Bronowanie $2 \times-$ Harrowing $2 \times$

C - Mocarz 75 WG w dawce 200,0 g/ha - Mocarz $75 \mathrm{WG}-200.0 \mathrm{~g} / \mathrm{ha}$ dose

$\mathrm{D}-$ Bronowanie $2 \times+$ Mocarz $75 \mathrm{WG}$ w dawce $100,0 \mathrm{~g} / \mathrm{ha}-$ Harrowing $2 \times+$ Mocarz $75 \mathrm{WG}-100.0 \mathrm{~g} / \mathrm{ha}$ dose

E - Mocarz $75 \mathrm{WG}$ w dawce $100,0 \mathrm{~g} / \mathrm{ha}-$ Mocarz $75 \mathrm{WG}-100.0 \mathrm{~g} / \mathrm{ha}$ dose 
Tabela 3. Skład gatunkowy i liczba chwastów na $\mathrm{m}^{2} \mathrm{w}$ łanie pszenicy jarej w zależności od sposobu regulacji zachwaszczenia i odmiany (średnie z lat 2008-2010)

Table 3. Species composition and number of weeds per $1 \mathrm{~m}^{2}$ in the spring wheat canopy in dependence on weed control methods and cultivars (means for 2008-2010)

\begin{tabular}{|c|c|c|c|c|c|c|c|}
\hline \multirow{2}{*}{$\begin{array}{l}\text { Dominujące gatunki chwastów } \\
\text { Dominant weed species }\end{array}$} & \multicolumn{5}{|c|}{$\begin{array}{l}\text { Sposoby regulacji zachwaszczenia } \\
\text { Weed control methods }\end{array}$} & \multicolumn{2}{|c|}{$\begin{array}{l}\text { Odmiany } \\
\text { Cultivars }\end{array}$} \\
\hline & A & $\mathrm{B}$ & $\mathrm{C}$ & $\mathrm{D}$ & E & Parabola & Monsun \\
\hline Chenopodium album $\mathrm{L}$. & 35,4 & 6,9 & 1,5 & 2,7 & 4,3 & 7,5 & 12,9 \\
\hline Stellaria media (L.) Vill. & 15,6 & 3,2 & 1,5 & 1,2 & 4,1 & 4,1 & 6,1 \\
\hline Viola arvensis Murray & 10,2 & 2,2 & 1,1 & 1,4 & 2,9 & 2,5 & 4,7 \\
\hline Galium aparine L. & 7,8 & 0,7 & - & - & 1,0 & 2,5 & 3,9 \\
\hline Galeopsis terahit $\mathrm{L}$. & 6,5 & 1,9 & - & 0,5 & 1,2 & 2,3 & 2,7 \\
\hline Cirisum arvense (L.) Scop. & 6,3 & 3,3 & 1,1 & 1,4 & 2,1 & 2,5 & 3,1 \\
\hline Galinsoga parviflora $\mathrm{Cav}$. & 5,6 & 1,8 & - & - & 0,2 & 1,5 & 3,5 \\
\hline Convolvulus arvensis $\mathrm{L}$. & 4,5 & 1,5 & 0,2 & - & 1,1 & 1,6 & 2 \\
\hline Fallopia convolvulus (L.) Á. Löve & 3,2 & 1,2 & 0,2 & 0,1 & 0,3 & 1,3 & 0,7 \\
\hline Capsella bursa-pastoris (L.) Medik. & 2,5 & 0,8 & 0,2 & 0,1 & 0,5 & 0,6 & 1 \\
\hline Elymus repens (L.) P. Beauv. & 1,9 & 0,5 & 0,4 & 0,0 & 0,2 & 0,4 & 0,8 \\
\hline $\begin{array}{l}\text { Pozostałe gatunki } \\
\text { Others species }\end{array}$ & 3,5 & 1,0 & 0,1 & 0,3 & 1,5 & 1,0 & 1,6 \\
\hline $\begin{array}{l}\text { Ogółem liczba gatunków } \\
\text { Total number of species }\end{array}$ & 17 & 15 & 9 & 11 & 14 & 12 & 14 \\
\hline
\end{tabular}

0,0 - gatunek występował w liczbie mniejszej niż $0,1 \mathrm{szt} . / \mathrm{m}^{2}-$ species occurring in less than $0.1 \mathrm{pcs} / \mathrm{m}^{2}$

- gatunek nie występował - species not occurring

A - Kontrola - Control

B - Bronowanie $2 \times-$ Harrowing $2 \times$

C - Mocarz 75 WG w dawce $200,0 \mathrm{~g} / \mathrm{ha}-$ Mocarz $75 \mathrm{WG}-200.0 \mathrm{~g} / \mathrm{ha}$ dose

D - Bronowanie $2 \times+$ Mocarz $75 \mathrm{WG}$ w dawce 100,0 g/ha - Harrowing $2 \times+$ Mocarz $75 \mathrm{WG}-100.0 \mathrm{~g} / \mathrm{ha}$ dose

E - Mocarz 75 WG w dawce 100,0 g/ha - Mocarz 75 WG - 100.0 g/ha dose

Tabela 4. Powietrznie sucha masa i zniszczenie chwastów w łanie pszenicy (średnie z lat 2008-2010)

Table 4. Air dry mass of weeds and degree of weed devastation in the wheat canopy (means for 2008-2010)

\begin{tabular}{l|c|c|c|c|c|c|c}
\hline \multirow{2}{*}{$\begin{array}{l}\text { Odmiany } \\
\text { Cultivars }\end{array}$} & \multicolumn{5}{c|}{ Sposoby regulacji zachwaszczenia - Weed control methods } & Średnia \\
\cline { 2 - 7 } & A & B & C & D & E & Mean \\
\hline Parabola & 62,3 & 15,1 & 5,9 & 7,5 & 19,2 & 22,0 \\
\hline Monsun & 70,8 & 18,4 & 8,6 & 10,9 & 24,3 & 26,6 \\
\hline Średnia - Mean & 66,6 & 16,8 & 7,3 & 9,2 & 21,8 & 24,3 \\
\hline
\end{tabular}

$\operatorname{NIR}(0,05)-\operatorname{LSD}(0.05)$

Sposoby regulacji - Weed control methods $-5,8$

Odmiany - Cultivars - r.n.

Sposoby regulacji $\times$ odmiany - Weed control methods $\times$ cultivars - r.n.

\begin{tabular}{l|c|c|c|c|c|c}
\hline \multicolumn{7}{c}{ Zniszczenie chwastów - Weed control [\%] } \\
\hline Parabola & - & 75,8 & 90,5 & 88,0 & 69,2 & 80,9 \\
\hline Monsun & - & 74,0 & 87,8 & 84,6 & 65,7 & 78,0 \\
\hline Średnia - Mean & - & 74,9 & 89,2 & 86,3 & 67,5 & 79,5 \\
\hline
\end{tabular}

r.n. - różnice nieistotne - not significant differences

A - Kontrola - Control

B - Bronowanie $2 \times-$ Harrowing $2 \times$

C - Mocarz $75 \mathrm{WG}$ w dawce 200,0 g/ha - Mocarz $75 \mathrm{WG}-200.0 \mathrm{~g} / \mathrm{ha}$ dose

$\mathrm{D}-$ Bronowanie $2 \times+$ Mocarz $75 \mathrm{WG}$ w dawce $100,0 \mathrm{~g} / \mathrm{ha}-$ Harrowing $2 \times+$ Mocarz $75 \mathrm{WG}-100.0 \mathrm{~g} / \mathrm{ha}$ dose

E - Mocarz 75 WG w dawce 100,0 g/ha - Mocarz 75 WG - $100.0 \mathrm{~g} /$ ha dose

Zastosowanie herbicydu w zalecanej dawce oraz bronowania z połową dawki herbicydu w porównaniu do pozostałych sposobów regulacji skuteczniej zniszczyło gatunki dominujące, w tym głównie: $C h$. album, S. media 
Tabela 5. Plon ziarna pszenicy jarej w zależności od sposobu regulacji zachwaszczenia i odmiany [t/ha] (średnie z lat 2008-2010) Table 5. Spring wheat yield in relation to weed control method and cultivar [t/ha] (means for 2008-2010)

\begin{tabular}{|c|c|c|c|c|c|c|}
\hline \multirow{2}{*}{$\begin{array}{l}\text { Odmiana } \\
\text { Cultivar }\end{array}$} & \multicolumn{5}{|c|}{$\begin{array}{l}\text { Sposoby regulacji zachwaszczenia } \\
\text { Weed control methods }\end{array}$} & \multirow{2}{*}{$\begin{array}{c}\text { Średnia } \\
\text { Mean }\end{array}$} \\
\hline & $\mathrm{A}$ & $\mathrm{B}$ & $\mathrm{C}$ & $\mathrm{D}$ & $\mathrm{E}$ & \\
\hline Parabola & 4,58 & 5,59 & 6,26 & 5,92 & 5,29 & 5,53 \\
\hline Monsun & 4,38 & 5,30 & 5,96 & 6,10 & 5,54 & 5,46 \\
\hline Średnia - Mean & 4,48 & 5,45 & 6,11 & 6,01 & 5,42 & 5,49 \\
\hline
\end{tabular}

$\operatorname{NIR}(0,05)-\operatorname{LSD}(0.05)$

Sposoby regulacji - Weed control methods $-0,451$

Odmiany - Cultivars $-0,272$

Sposoby regulacji $\times$ odmiany - Weed control methods $\times$ cultivars - r.n.

r.n. - różnice nieistotne - not significant differences

A - Kontrola - Control

B - Bronowanie $2 \times-$ Harrowing $2 \times$

C - Mocarz $75 \mathrm{WG}$ w dawce 200,0 g/ha - Mocarz $75 \mathrm{WG}-200.0 \mathrm{~g} / \mathrm{ha}$ dose

$\mathrm{D}-$ Bronowanie $2 \times+$ Mocarz $75 \mathrm{WG} \mathrm{w}$ dawce $100,0 \mathrm{~g} / \mathrm{ha}-$ Harrowing $2 \times+$ Mocarz $75 \mathrm{WG}-100.0 \mathrm{~g} / \mathrm{ha}$ dose

E - Mocarz 75 WG w dawce 100,0 g/ha - Mocarz 75 WG - $100.0 \mathrm{~g} /$ ha dose

i $V$. arvensis eliminując całkowicie $G$. aparine. Badania Kapelusznego i wsp. (2012) potwierdzają dobrą efektywność różnych metod regulacji zachwaszczenia w pszenicy jarej w stosunku do wymienionych taksonów, uzależniając jednak skuteczność tych zabiegów od terminu ich stosowania, zwłaszcza dla G. aparine.

Średnio w okresie badań stwierdzono istotne zmniejszenie powietrznie suchej masy na wszystkich obiektach w stosunku do obiektu nieodchwaszczonego o $63,5 \%$ (tab. 4). Ograniczenie zachwaszczenia wahało się od 3-krotnej po zastosowaniu połowy dawki herbicydu Mocarz 75 WG do 9-krotnej po aplikacji w dawce zalecanej. Stopień zniszczenia chwastów ogółem wynosił odpowiednio 67,5 i 89,2\%. Zbliżoną skuteczność chwastobójczą w pszenicy jarej uzyskali w swoich badaniach Cierpiała i Wesołowski (2009) oraz Urban i wsp. (2011) stosując pełne dawki herbicydów Apyros 75 WG i Starane Super 101 SE oraz Starane 250 EC i Chwastox Turbo 340 SL. Na pozostałych obiektach uzyskano obniżenie powietrznie suchej masy chwastów odpowiednio po bronowaniu zasiewów o 74,9\%, a po aplikacji obniżonej o połowę dawki herbicydu o $67,5 \%$. Nie stwierdzono dowiedzionego statystycznie wpływu odmiany oraz interakcji czynników doświadczenia na redukcję powietrznie suchej masy chwastów.

Zastosowane sposoby regulacji, a zwłaszcza aplikacja zalecanej dawki herbicydu oraz obniżonej po wcześniejszym bronowaniu istotnie wpływały na plonowanie pszenicy w kolejnych latach badań (tab. 5). Dla obiektu, gdzie zastosowano Mocarz 75 WG w pełnej dawce uzyskano istotnie wyższy plon ziarna $\mathrm{w}$ porównaniu z obiektem kontrolnym, średnio o 36,7 i 36,1\% dla odmian Parabola i Monsun. Zwiększenie plonu ziarna w odniesieniu do kontroli na obiektach z regulacją mechaniczną uzupełnioną połową dawką herbicydu wynosiło średnio od 29,2 (Parabola) do 39,3\% (Monsun). Skuteczność metody mechaniczno-chemicznej $\mathrm{z}$ zastosowaniem bronowania i obniżonej dawki herbicydu w zwalczaniu chwastów w pszenicy jarej i ozimej potwierdzają badania wielu autorów (Knezevic i wsp. 2003; Kierzek i Wachowiak
2004; Brzozowska i Brzozowski 2008; Wesołowski i Boniek 2009).

Krawczyk i Kaczmarek (2008) oraz Haliniarz i Kapeluszny (2012) wskazują na istotny wzrost plonu ziarna pszenicy jarej z obiektów odchwaszczanych herbicydem Chwastox Trio 540 SL w dawkach zredukowanych (do 1,0 1/ha) w porównaniu do obiektu kontrolnego. Ponadto plony ziarna pochodzące $\mathrm{z}$ obiektów $\mathrm{z}$ zredukowanymi i pełnymi dawkami herbicydów są podobne.

Również w badaniach własnych wzrost plonu ziarna pszenicy jarej $\mathrm{w}$ odniesieniu do kontroli na obiektach z połową dawki herbicydu był istotny i wynosił średnio od 15,5 (Parabola) do 26,5\% (Monsun). W odróżnieniu od cytowanych badań różnice $\mathrm{w}$ plonie pomiędzy obiektami z zalecaną dawką oraz $\mathrm{z}$ dawką obniżoną do $50 \%$ po wcześniejszym bronowaniu a obiektami z połową dawki herbicydu były istotne, co potwierdzono również we wcześniejszych badaniach autora (Buczek i wsp. 2010). Rozbieżność wyników badań można tłumaczyć tym, iż skuteczność chwastobójcza mniejszych dawek herbicydów zależy od wielu czynników, takich jak rodzaj zawartej w nich substancji czynnej, a także stopień zachwaszczenia pola, faza rozwojowa chwastów czy kondycja rośliny uprawnej (Domaradzki i wsp. 2003; Swanton i wsp. 2008).

Dwukrotne bronowanie odmian pszenicy powodowało istotną tendencję wzrostu plonu ziarna względem obiektów bez jakiejkolwiek pielęgnacji. Uzyskany plon ziarna był zbliżony do stwierdzonego na obiektach z połową dawki herbicydu. Bronowanie zasiewów pszenicy jarej nie powodowało natomiast podobnego efektu zwyżki plonu ziarna do pełnej dawki stosowanego herbicydu, co uzyskano w badaniach Cierpiały i Wesołowskiego (2009). Plony ziarna obu odmian pszenicy jarej w obrębie sposobów regulacji zachwaszczenia nie różniły się istotnie między sobą. Zróżnicowane istotnie plony wystąpiły tylko na obiektach $\mathrm{z}$ regulacją mechaniczną i mechanicznochemiczna, gdzie odmiana Parabola miała o 5,0\% wyższe plony od odmiany Monsun. 


\section{Wnioski / Conclusions}

1. Najlepsze efekty chwastobójcze stwierdzono na obiektach, gdzie stosowano zalecaną dawkę herbicydu i dwukrotne bronowanie zasiewów uzupełnione połową dawki herbicydu.

2. Zastosowanie metody mechaniczno-chemicznej pozwoliło na zmniejszenie dawki herbicydu o $50 \%$ bez straty skuteczności chwastobójczej, umożliwiając redukcję chwastów i plonowanie odmian pszenicy na poziomie uzyskanym po zastosowaniu pełnej rekomendowanej dawki herbicydu.

3. Dobór odmian pszenicy nie miał wpływu na redukcję powietrznie suchej masy oraz stopień zniszczenia chwastów ogółem.

\section{Literatura / References}

Brzozowska I., Brzozowski J. 2008. Skuteczność odchwaszczania pszenicy ozimej w zależności od sposobu pielęgnacji i nawożenia azotem. Acta Agrophys. 11 (2): 345-356.

Buczek J., Tobiasz-Salach R., Bobrecka-Jamro D. 2010. Skuteczność stosowania pełnych i zredukowanych dawek herbicydów w pszenicy jarej. Ann. UMCS, Sec. E, 65 (1): 9-17.

Cierpiała R., Wesołowski M. 2009. Wpływ terminu bronowania na plonowanie pszenicy jarej. Fragm. Agron. 26 (3): $25-33$.

Domaradzki K., Kieloch R., Rola H. 2003. Skuteczność herbicydów w zależności od dawki i fazy rozwojowej chwastów. [Herbicide efficacy depending on the dose and stage of development of weeds]. Prog. Plant Prot./Post. Ochr. Roślin 43 (1): 109-114.

Haliniarz M., Kapeluszny J. 2012. Reakcja trzech odmian pszenicy jarej na zmniejszenie zalecanej dawki herbicydu Chwastox Trio 540 SL. Fragm. Agron. 29 (2): 33-42.

Kapeluszny J., Dyńska M., Haliniarz M. 2012. Wpływ sposobów pielęgnacji na zachwaszczenie dwóch linii pszenicy twardej (Triticum durum Desf.). [The effect of weed control methods on weed infestation of two durum wheat (Triticum durum Desf.) lines]. Prog. Plant Prot./Post. Ochr. Roślin 52 (2): 287-293.

Kierzek R., Wachowiak M. 2004. Efektywność zwalczania chwastów w pszenicy jarej z użyciem mechanicznej i chemicznej metody odchwaszczania. [The effectiveness of weed control in spring wheat using mechanical and chemical methods of weed control]. Prog. Plant Prot./Post. Ochr. Roślin 44 (2): 831-835.

Knezevic M., Durkic M., Knezevic I., Antonic O., Jelaska S. 2003. Effects of tillage and reduced herbicide doses on weed biomass production in winter and spring cereals. Plant Soil Environ. 49 (9): 414-421.

Krawczyk R., Kaczmarek S. 2008. Wpływ stosowania obniżonych dawek herbicydów na plon i jakość ziarna pszenicy jarej. Fragm. Agron. 25 (1): 188-197.

Krawczyk R. 2009. Wpływ bioróżnorodności gatunkowej chwastów na skuteczność obniżonych dawek herbicydów i terminu ich stosowania w warunkach różnej gęstości siewu pszenicy jarej na przykładzie produkcji biomasy oraz diaspor Chenopodium album L. Pam. Puł. 150: 181-193.

Salonen J. 1992. Efficacy of reduced herbicide doses in spring cereals of different competitive ability. Weed Res. (32) 6: $483-491$.

Swanton C.J., Mahoney K.J., Chandler K., Gulden R. 2008. Integrated weed management: knowledge based weed management systems. Weed Sci. 56: 168-172.

Urban M., Gil Z., Smorąg A., Grządka M. 2011. Wpływ zróżnicowanych dawek herbicydów na redukcję zachwaszczenia i plonowanie odmian pszenicy jarej. [The effect of varied herbicide doses on weed infestation and yielding of spring wheat varieties]. Prog. Plant Prot./Post. Ochr. Roślin 51 (2): 707-713.

Wesołowski M., Boniek Z. 2009. Wpływ przedplonu i sposobu pielęgnacji na zachwaszczenie pszenicy ozimej. [The effect of preceding crop and cultivation on weed infestation of winter wheat field]. Prog. Plant Prot./Post. Ochr. Roślin 49 (1): 357-360. 